\title{
Developing new products and services in entrepreneurial contexts
}

\author{
Duygu Keskin, Renee Wever and J.C. Brezet
}

Delft University of Technology, Faculty of Industrial Design Engineering, The Netherlands

\subsection{Introduction}

Research on sustainable PSS thus far, as also seen in this volume, has created an understanding of what role design might play in creating sustainable solutions for society and what tools and approaches designers might adopt. Nevertheless, integrating sustainability into the design process is not an easy matter. As York and Venkataraman (2010) state, '...larger environmental dilemmas, such as human-induced climate change, inherently involve uncertainty'. The existence and severity of issues related to sustainability are controversial, exacerbating the difficulty to identify the best solutions to address them. This challenge requires 'actions in the face of ambiguity' (York and Venkataraman 2010).

While established firms often prefer a design space with a clear vision and pre-defined objectives, ambiguity is the essence of the entrepreneurial context. Entrepreneurial action is driven by uncertainty in order to transform it into opportunity. In this way 'an alternative future is created rather than anticipated' (York and Venkataraman 2010). Therefore, the aim of this chapter is to explore how new ventures develop PSS innovations that contribute to sustainability and to investigate the role of design in this process. 


\subsection{Models of product innovation and PSS innovation}

The innovation process might unfold in various fashions depending on the level of uncertainty involved in respect to the technology and market. As Hellman (2007) points out, in the case of radical innovations the uncertainty might be due to the immature state of technology development (i.e. technical uncertainty), as well as the difficulty in predicting if and when markets will adopt the new product (i.e. market uncertainty). The higher the level of novelty and uncertainty, the more complex, disorderly and uncontrollable is the process (Van de Ven et al. 1999). The following paragraphs review the various models of the product innovation process. The rational models (e.g. Roozenburg and Eekels 1995; Cooper et al. 2002) mainly stem from research on established organisations, are goaloriented, suggest an analytic logic and are visualised in a linear fashion. On the other hand, non-rational models (e.g. Thomke et al. 1998; Lynn et al. 1996) stem particularly from radical innovation research, suggesting an experimental logic involving a process of learning.

In early representations, the innovation process is commonly characterised as an orderly, chronological process (Buijs 2003). An early model developed by the design theorist Bruce Archer (1971) includes six successive steps of strategic planning, research, design, development, manufacturing and marketing setup, and production. Similarly, the Delft Design Method, developed by Roozenburg and Eekels (1995), consists of diverging and converging steps of policy formulation, idea finding, strict development and realisation. Each step consists of a sequence of analysis, synthesis, simulation and evaluation. The process starts with the analysis of the design situation, followed by a synthesis of possible solutions and a simulation in order to judge the possible solutions against the original design situation. The final step is the evaluation of the design solution. While the divergence is oriented towards getting as many alternatives as possible, the convergence is oriented towards choosing the best and most promising of those alternatives. At the Faculty of Industrial Design Engineering at Delft University of Technology, specific design tools are taught to improve the performance of these diverging and converging activities. For example, 'brainstorming' and 'morphological boxes' are creativity tools that support the diverging idea generation phase and 'program of requirements' is a tool that helps to converge and screen the multiple ideas created in prior phases (Buijs 2003). Within the field of New Product Development (NPD), a similar model is Cooper et al.'s (2002) frequently cited 'stage-gate' process model that starts with the definition of a problem and ends with the commercialisation of an end product.

These linear models suggest that the innovation process is a sequence of activities that starts with the definition of a problem and ends with the commercialisation of an end product (Archer 1971; Roozenburg and Eekels 1995; Dorst 1997; Buijs 
and Valkenburg 2000; Cooper et al. 2002; Buijs 2003). The NPD process is often portrayed as a linear model where a product proceeds from one phase to the other (Roozenburg and Eekels 1995) and is thus goal-oriented and visualised in consecutive steps.

Similarly, the PSS innovation process has so far been conceptualised as a linear model. Based on Rozenburg and Eekels's (1995) product development process, Brezet et al. (2001) have developed the 'Design of Eco-efficient Services' (DES) methodology in order to enable service and product designers in Eco-efficient Service (ES) design using a systematic approach (Figure 3.1). The process starts with an exploration phase involving various actions such as forming a project team of companies and partners, formulating a vision and goals, analysing the environmental impact of the current situation and identifying future users. The expected outcome of this phase is a business coalition or a new business with a mission. The steps that follow the exploration phase are similar to the product innovation models explained above: policy formulation, idea finding, strict development, realisation and evaluation. The process is driven by analysis requiring the use of various business, design and environmental impact assessment tools, such as market research, strategy and policy tools (e.g. SWOT $=$ Strengths, Weaknesses, Opportunities, Threats), a quick environmental assessment tool (META-matrix $=$ Materials, Energy, Toxic substances, Added value), benchmarking, backcasting, Life Cycle Assessment scenarios, stakeholder analysis, Ecocosts/value, blueprinting, and other tools (Brezet et al. 2001).

Throughout the process one or more sub-processes might be required. For example, due to a lack of expertise a company might outsource part of the development or even the whole product development. Such a sub-process has been depicted in Figure 3.1.

Similarly, the most up-to-date PSS methodology 'Methodology for System Design for Sustainability (MSDS)' described in Part 1, Chapter 4 of this book is organised in stages, processes and sub-process (Table 4.1, Part 1). The new approaches and insights developed throughout the LeNS project are integrated into this methodology, i.e. 'Sustainability-Orienting Processes' and 'Design for a Sufficient Economy Processes'. The MSDS starts with a phase of analysis on project proposers, the socio-technical regime, macro trends, cases of excellence for sustainability, design priorities, and a sufficiency need assessment. The following steps are similar to the approaches mentioned above: exploring opportunities, selecting the most promising ideas (based on detailed environmental, socio-ethical and economic criteria), designing system concepts, designing and engineering the system, and communicating. Each of these steps includes various tools for sustainability assessment, stakeholder analysis, future trends analysis, checklists and guidelines (see Part 1, Chapter 4, Section 4.2). The methodology is analysis and assessment driven and oriented towards a goal, i.e. a set of products and services that makes up the most sustainable offer. 
Figure 3.1 DES methodology

Source: Brezet et al. 2001

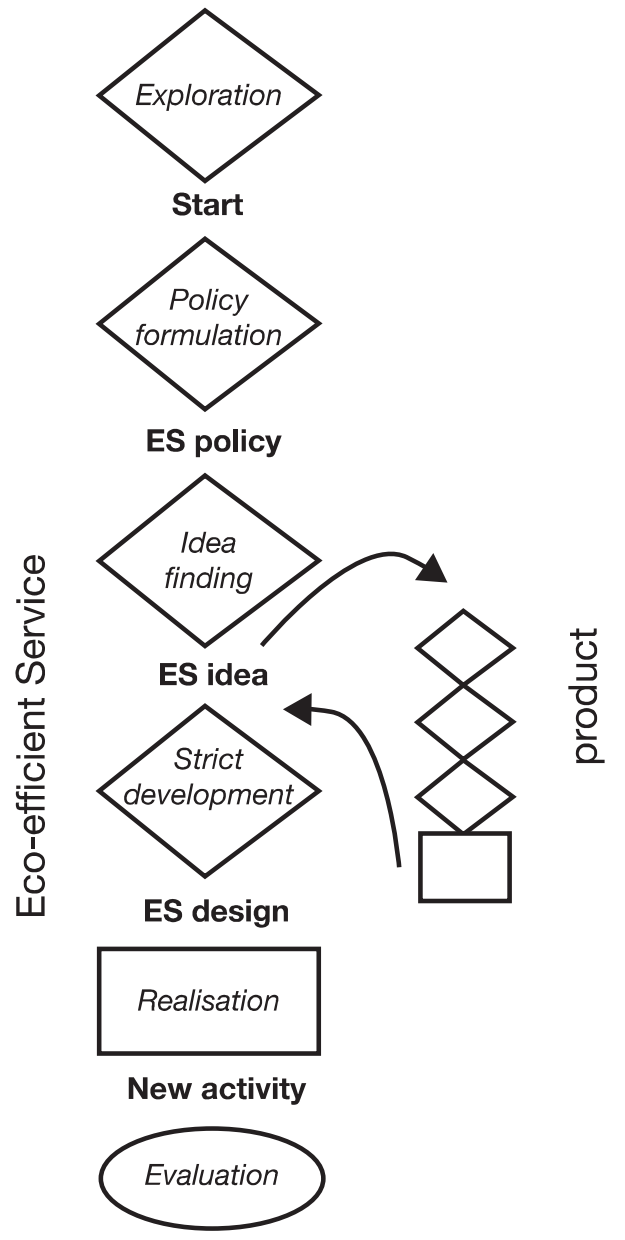

Despite the analytic logic and linear representations outlined above, in practice the innovation process is more chaotic and unstructured (Buijs 2003) and may require an experimental logic (Hellman 2007). This is true particularly in the case of radical innovations; as Lee et al. (2004) suggest, 'experimentation is fundamental to solving problems for which outcomes are uncertain and where critical sources of information are nonexistent or unavailable'. Moreover, integrating sustainability into the process makes it more complex since issues of sustainability deal with future options and often require action in the absence of concrete performance data, particularly regarding the social and environmental consequences of the innovation in development. Therefore, the non-rational view of the innovation process is illustrated as a learning process with intermediate outcomes (Schön 1967; Lynn et al. 1996) unlike a single product as illustrated in NPD models. Considering the technological and market uncertainties involved within radical innovations, 'the innovation process is characterised as a highly uncertain journey of exploration and learning and modeled as a dynamic process of parallel activities in technology development, early applications and continuous learning' (Hellman 2007). In order to decrease the uncertainty linked to radical innovation, some 
scholars have proposed different management practices such as 'experimentation', 'trial and error' and 'probe and learn' (Garud and Van de Ven 1992; Thomke et al. 1998; Lynn et al. 1996).

Experimentation 'is often carried out using simplified versions of the eventually-intended test object' (Thomke et al. 1998). When experiments are carried out in succession, the process is called 'trial and error' (Garud and Van de Ven 1992; Thomke et al. 1998). However, as Silberzahn (2011) emphasises, trial and error has limits with regards to the actual learning it provides because the experiments are conducted with prototypes in controlled conditions. Therefore, the reliability of these prototypes is open to debate.

On the other hand, 'probe and learn' involves experimentation in real markets. It requires probing with the immature versions of the products, i.e. introducing an early version of the product to an initial market, learning from that experiment and probing again (Lynn et al. 1996). A probe in this process is a means for learning about the technology and markets. For example, a probe might reveal information on if and how the technology can be scaled-up and/or which market segments are more interested in certain product features (Lynn et al. 1996). 'Trial and error' and 'probe and learn' have similar characteristics such as being iterative and proceeding in successive affordable steps; however a probe is more effective than a trial in resolving market-related uncertainties (Silberzahn 2011).

In essence, all of these practices point to the difficulty of making rational decisions in an uncertain context based on only research and analysis due to the limited information they reveal. There is a need for experimentation of various forms in order to decrease the technical and/or market uncertainty, as well as uncertainty related to the sustainability performance of the innovation. But how does this happen in an entrepreneurial setting characterised by few resources?

\subsection{An emerging theory of entrepreneurship: effectuation}

The concept of uncertainty has recently been addressed in the domain of entrepreneurship though an emerging theory called effectuation. Taking the study of Knight (1921) on 'risk' and 'uncertainty', Sarasvathy (2001) examines how expert entrepreneurs address uncertainty through a series of stakeholder 'commitments'.

Differentiating 'risk' from 'uncertainty', Knight (1921) describes risk as a measurable uncertainty in which the probability of an outcome in a set of future states is known through calculation or past experience. On the other hand, in the case of uncertainty the set of future states does not exist due to the uniqueness of the situation; hence it is impossible to predict the distribution or probability of the outcome. This makes planning a difficult and irrelevant activity (Burns and Stalker 1961). Therefore, Sarasvathy (2001) proposes an effectual logic: i.e. getting 
the commitment of stakeholders at early stages of business development helps reduce the uncertainty. She claims that this type of reasoning is particularly useful and effective in domains such as the introduction of new products and services in new markets, where traditional marketing techniques are ineffective (Sarasvathy 2001).

Effectual logic is the inverse of causal logic (i.e. predictive reasoning), which is predominantly taught in business schools (Sarasvathy 2001) and often in design schools (see the product design methodologies presented in the previous paragraphs). Causal logic is goal driven; means are selected in order to achieve a given goal. In contrast, effectual logic does not begin with a pre-defined goal. Goals emerge from a given set of means, and therefore the process is means driven. Entrepreneurs, pragmatically, start thinking of what they can do with their given sets of means. They start with three categories of means: 1) who they are (their skills and abilities); 2) what they know (their education and expertise); and 3) whom they know (their social and professional networks). They then begin to imagine and implement possible effects that can be created and are worth creating (Sarasvathy 2001). They move almost directly into action and interaction with other people. Those who commit to the new venture bring in new means and goals (Figure 3.2). The result is an expanding cycle of means and converging cycle of goals. This is how a future market is co-created, and the core mechanism of this process is the commitment of a growing network of stakeholders to the venture (Sarasvathy 2008).

\section{Figure 3.2 Dynamic model of effectuation}

Source: Sarasvathy and Dew 2005. With kind permission from the authors

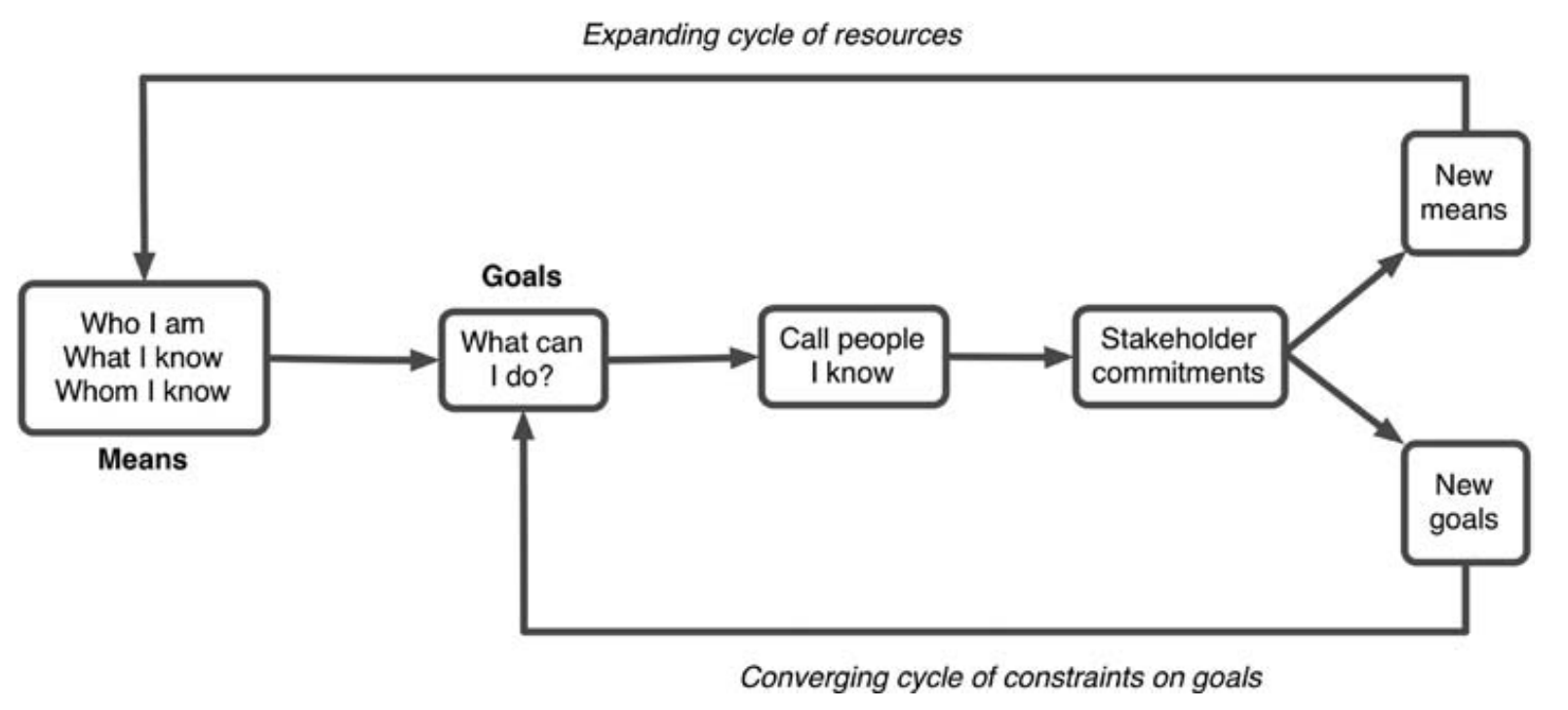


Effectuators see the product (idea/concept) as transformable and not completely pre-determined. According to Sarasvathy (2008: 113), alternatives matter in a different way in effectual transformations from those in search and selection processes. In a search and selection process, alternatives are selected from a set of all possible alternatives. In this process, commitment to a product is committing to it as the goal of action and the resources are allocated between alternatives to achieve the pre-selected goal. In an effectual process, on the other hand, alternatives are seen as possible transformations of existing realities. In other words, committing to a product means committing to a certain course of action that may or may not lead to any envisioned product (Sarasvathy 2008).

In other words, when a particular effect has already been chosen such as a target market segment or specific product functionality, the entrepreneurs will search for stakeholders based on that pre-defined effect. Effectual logic, however, does not assume such pre-existent markets or products. People that entrepreneurs are able to bring together determine the markets and products that are created (Sarasvathy 2001).

\subsection{PSS innovation process in effectuation}

The previous paragraphs explained how new ventures are created effectually in uncertain contexts. The objective of this section is to illustrate the role of design iterations within the model of effectuation and explain why design-inspired effectuation might be a suitable approach to developing PSS innovations.

Within the context of product innovation, as well PSS innovation, when developing new businesses, entrepreneurs not only go through a cycle of stakeholder interactions, but also a cycle of design iterations. It is not only stakeholders' commitments but also design iterations that enable entrepreneurs to converge goals, decrease uncertainty and transform the product or PSS. Figure 3.3 shows how design iterations are integrated into Sarasvathy's (2008) dynamic model of effectuation. The cycle of stakeholder interactions represents the model of effectuation and explains how goals emerge from the varied and diverse aspirations of the entrepreneurs and the people with whom they interact. Commitment is the core mechanism to this process (Sarasvathy 2008).

Design iterations, on the other hand, are cycles of developing capabilities and competences of the entrepreneurial team; at the same time they are cycles of learning about the limitations and opportunities related to the technology at hand. The outcome of a design iteration might be a sketch, a computer rendering, a prototype or a probe that enables the team to learn about what it actually can deliver. While the purpose of a design iteration might be learning about the technology and its potential, it can also be ensuring the commitment of stakeholders (i.e. demonstrating the proof of principle). 
Each innovation process is unique and there is no one formula that can explain how and why the events happen as they do. In an innovation process, design iterations and stakeholder interactions might occur in parallel and/or one after the other. They occur in varying frequencies and sequences. A stakeholder interaction might be the trigger of a design iteration and the outcome of a design iteration might be the trigger for a stakeholder interaction. The aim of the model of designinspired effectuation is to illustrate this difference and variety as well as to introduce design iterations as an important factor in venture development.

Figure 3.3 PSS innovation within the entrepreneurial context

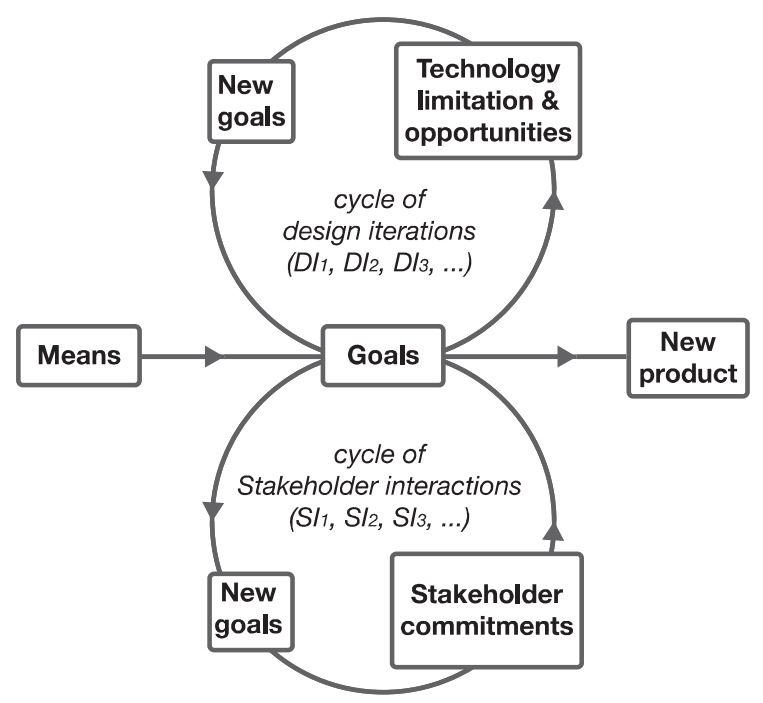

\subsection{SDC case}

This section will illustrate the model with a case study. The Sustainable Dance Club (SDC) was initiated in 2005 as a project by Rotterdam-based network organisation Enviu and architecture firm Döll. The project started with the aim of making the clubbing scene more sustainable through reducing the environmental impact of clubs and inspiring young people to adopt a sustainable lifestyle.

During the initiation period, the project team had developed various ideas related to energy, waste, materials and water in clubs. The initial business idea was to develop various products in order to decrease the environmental impact of the clubs while offering consultancy services to help clubs achieve this. SDC as a company started in 2006 when an energy generating dance floor was selected as the most promising product idea (Figure 3.4). The Sustainable Dance Floor (SDF) uses people's movement as a sustainable source of energy. The energy produced through movement is converted into electricity and used for LED lights embedded within the floor. The floor thereby interacts with the dancers and contributes to 
the collective experience. The feedback system is thus one of the most important aspects: people dancing on the floor must understand that they are the ones powering it and therefore the floor lights up when stepped on.

\section{Figure 3.4 The Sustainable Dance Floor}

Source: Sustainable Dance Club

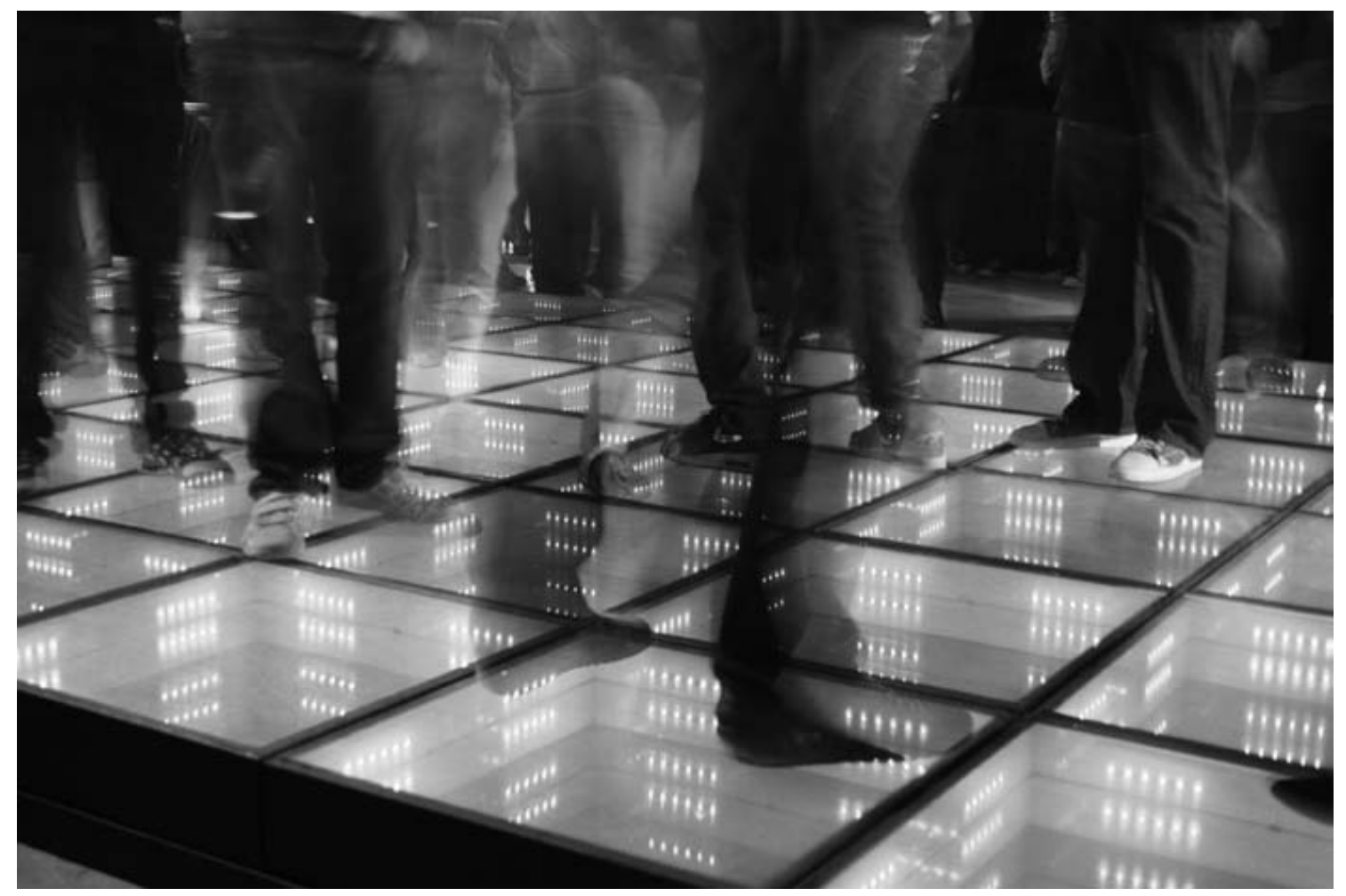

The initial business idea was to offer the floor in a rental scheme, i.e. as a 'useoriented PSS innovation' (for more on PSS innovation typologies, see Part 1, Chapter 2, Section 2.1.4). Meanwhile, a seven-step approach to successfully implementing sustainability for the clubbing and events market has been developed. The approach includes helping clients to establish ambitions, analyse their current business, set goals, organise workshops in order to develop solutions to achieve the agreed goals, as well as translate those solutions into actions.

When the development of the dance floor was initiated, the company aimed at developing a floor that would generate sufficient electricity for the energy needs of a whole club. In 2006, the feasibility of the idea was tested through a preliminary concept developed by a design student of the Faculty of Industrial Design Engineering at Delft University of Technology $\left(D I_{1}\right)$. The first prototypes were not as efficient as anticipated: the amount of human power transformed into electricity by dancing is not huge. Meanwhile, SDC started interacting with various clubs in order to establish their reaction to the concept of an energy generating dance floor $\left(S I_{1}\right)$ and learned that energy is not high on the clubs' priority lists. The clubs' main 
costs are actually the drinks, personnel, communications and artists, while energy is only a fraction of the expenditure. For clubs, it is more important to attract people to the club than save energy. Second, the club owners supported the idea of sustainability provided it was not too expensive: the price of the floor for buying or renting was not considered affordable. Third, the unique selling point of the floor is its power to attract people, i.e. 'we are a sustainable club, and we offer sustainable entertainment'. But it was not clear to clubs whether an SDF-compared to the alternative products/services-was the most effective and cost-efficient way of attracting clubbers.

Although the first prototypes were not as efficient as expected and the clubs were reluctant to buy the product, SDF was still presented to the public at various events throughout 2006 and 2007. The idea of an energy-generating dance floor received enormous national and international media attention. Particularly, businesses, museums and event organisations were eager to use the floor to showcase sustainability in public events. In addition, the SDF concept received very positive reactions from clubbers who participated in user tests $\left(S I_{2}\right)$.

The limitations in transforming human power into sufficient energy for a whole club (outcome of $D I_{1}$ ), the reluctance of clubs to buy the floor (outcome of $S I_{1}$ ) and enormous positive feedback from media and clubbers (outcome of $\mathrm{SI}_{2}$ ) stimulated SDC to shift its market and business focus. The company decided to put its efforts into making the floor an attractive promotion medium for large organisations that like to showcase sustainability in public events. This direction would further emphasise the sustainability aspects of the floor and communicate sustainability to the audience in a more effective way. Currently, the main business of SDC is to rent and, when possible, sell the floor to event organisations and museums. Meanwhile, the company has concentrated effort into the development and optimisation of the technology in terms of cost and performance with the aim of fitting it into the requirements of the clubs $\left(D I_{2}\right)$.

The idea of an energy-generating dance floor has continued to receive attention of various organisations $\left(S I_{3}\right)$. This has stimulated the idea of using the technology at locations with large volumes of people walking, such as stadiums, airports, railway stations, shopping centres, (public) buildings and city squares (outcome of $S I_{3}$ ); see Figure 3.5. Since 2010, SDC has been developing the Sustainable Energy Floor (SEF) for cost-effective, large-scale applications $\left(D I_{3}\right)$. The electricity produced through SEF can be fed back into the grid or used to power local systems such as (LED) streetlights or information and signage systems. A small amount of the energy can also be used to give feedback to users, e.g. by illuminating parts of the floor modules. 
Figure 3.5 The Sustainable Energy Floor illustrated in a shopping mall Source: Sustainable Dance Club

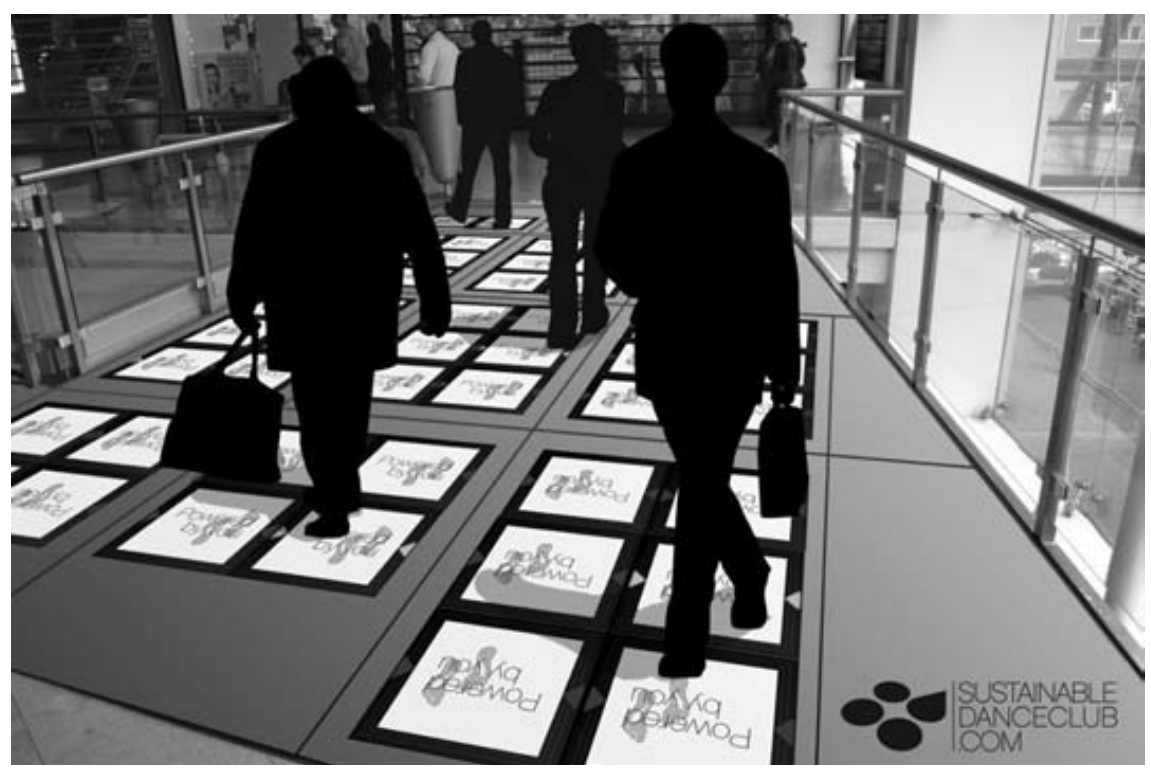

\subsection{Conclusions}

Earlier approaches to the design and development of products and services for sustainability have contributed to the understanding of what role design might play in creating a sustainable society. Nevertheless, the tools and approaches developed thus far tend to be rather conceptual, normative and prescriptive (Berchicci 2005). Furthermore, the high levels of uncertainty involved in sustainable innovation and the organisational context in which it is embedded have implications for the innovation process and how it is managed. Links to current organisational and entrepreneurial theories need to be strengthened. Therefore, this chapter aimed at explaining why 'design-inspired effectuation' is a suitable approach in developing product and PSS innovations in an entrepreneurial context. Although integration of design into the effectuation is not yet well researched, this chapter presented a first model of design-inspired effectuation, which is illustrated within a case study. In addition to the goal-driven product and PSS methodologies, effectuation offers an alternative approach to be considered when developing sustainable products and services. 


\section{References}

Archer, B.L. (1971) Technological Innovation: A Methodology (London: Inforlink).

Berchicci, L. (2005) The Green Entrepeneur's Challenge: The Influence of Environmental Ambition in New Product Development. Doctoral dissertation. Delft University of Technology, Delft.

Brezet, J.C., Bijma, A., Ehrenfeld, J. and Silvester, S. (2001) The design of eco-efficient services. Design for Sustainability Program. Delft University of Technology, Delft.

Buijs, J. (2003) 'Modelling Product Innovation Processes: from Linear Logic to Circular Chaos', Creativity and Innovation Management 12 (2): 766-93.

Buijs, J. and Valkenburg R. (2000) Integrale Productontwikkeling (Utrecht: Lemma).

Burns, T. and Stalker, G.M. (1961) The Management of Innovation (London: Tavistock).

Cooper, R.G., Edgett, S.J. and Kleinschmidt, E.J. (2002) 'Optimizing the stage-gate process: What best practice companies are doing' Research Technology Management 45(5).

Dorst, K. (1997) Describing Design: A comparison of paradigms. Doctoral dissertation. Delft University of Technology, Delft.

Garud, R. and Van de Ven, A.H. (1992) 'An empirical evaluation of the internal corporate venturing process', Strategic Management Journal 13: 93-109.

Hellman, H. (2007) Probing Applications: How Firms Manage the Commercialisation of Fuel Cell Technology. Doctoral dissertation. Delft University of Technology, Delft.

Knight, F.H. (1921) Risk, uncertainty and profit (1933 edn) (New York: Houghton Mifflin).

Lee, F., Edmondson, A.C., Thomke, S.H. and Worline, M. (2004) 'The mixed effects of inconsistency on experimentation in organizations', Organization Science 15(3): 310-326.

Lynn, G.S., Morone, J.G. and Paulson A.S. (1996) 'Marketing and discontinuous innovation: the probe and learn process', California Management Review 38(3): 8-37.

Roozenburg, N.F.M. and Eekels, J. (1995) Product Design: Fundamentals and Methods (New York: Wiley).

Sarasvathy, S.D. (2001) 'What makes entrepreneurs entrepreneurial?' www.entreprnr.net/ assets/WhatMakesEntrepreneurs.pdf, accessed 24 June 2013.

Sarasvathy, S.D. (2008) Effectuation: elements of entrepreneurial expertise. New Horizons in Entrepreneurship (Cheltenham, UK; Northampton, MA: Edward Elgar Publishing).

Sarasvathy, S.D. and Dew, N. (2005) 'Entrepreneurial logics for a technology of foolishness', Scandinavian Journal of Management 21(4): 385-406.

Schön, D.A. (1967) Technology and Change: The New Heraclitus (New York: Delacorte Press).

Silberzahn, P. (2011) 'Flexibility and Commitment in the Management of Uncertainty in Nascent Markets', Academy of Management Annual Meeting, San Antonio, Texas.

Thomke, S.H, von Hippel, E. and Franke, R. (1998) 'Modes of Experimentation: An Innovation Process-and Competitive-Variable', Research Policy 27(3): 315-332.

Van De Ven, A.H., D.E. Polley, R. Garud and S. Venkataraman (1999) The Innovation Journey (Oxford: Oxford University Press).

York, J.G. and Venkataraman, S. (2010) 'The Entrepreneurship-Environment Nexus: Uncertainty, Innovation and Allocation', Journal of Business Venturing 25(5): 449-463. 